\title{
Non-Consequentialist Theories of Animal Ethics ${ }^{1}$
}

The debate over how to construct a broadly animal-protective ethical theory has, mercifully, moved beyond the old Singer-versus-Regan duality that was dominant for so long. On the consequentialist side of things, Jeff McMahan has developed a nuanced view that builds off Singer while arguably avoiding certain shortcomings in Singer's own position. ${ }^{2}$ On the other side, Regan's view has faded from the scene and instead non-consequentialists have been hard at work, especially in just the last 10 years, developing new theories that, in my view, are much better than Regan's. ${ }^{3}$ My plan here is to review and critique three compelling and philosophically rich efforts along those lines: Christine Korsgaard's neo-Kantianism, Mark Rowlands's contractarianism, and Martha Nussbaum's capability-based approach. This is not meant to suggest that other recent non-consequentialist work in animal ethics is unworthy of our attention. Rather, these three theorists happened to have piqued my interest and that of many other philosophers, and so with the limited space I have here it seems most sensible to focus on them.

\footnotetext{
${ }^{1}$ This paper was presented at the Annual Meeting of the Society for Applied Philosophy in July 2015. I thank the audience there for its feedback.

${ }^{2}$ See, for instance, McMahan 2002. McMahan's view on killing animals can be found in chap. 3, and his amendment to Singer's view can be found on pp. 347-62. McMahan is not a consequentialist, I realize, since he holds that some beings possess moral inviolability. However, it's accurate to say that he's a consequentialist about animal ethics since he considers almost all animals to lack moral inviolability and contends, further, that when inviolability is out of the picture the wrongness of killing a being varies with the time-relative strength of the interest the being has in continuing to live. (Rahul Kumar agrees, calling McMahan's interest-weighing theory "broadly, though not officially, utilitarian”; see Kumar 2008:64.) See also McMahan’s (2005:534-5) comments on killing animals for medical research.

It should be noted, finally, that in more recent work McMahan has flirted with the possibility of adopting an even more consequentialist view regarding the ethics of killing. See McMahan 2008.

${ }^{3}$ Since my goal here is to review new non-consequentialist work in animal ethics, I omit a critique of Regan's theory here. But what I would have said has been said already, by Mark Rowlands (2009:8693).
} 


\section{Korsgaard's Neo-Kantianism}

I begin with Korsgaard because she sets the agenda for non-consequentialist theories of animal ethics in what strikes me as precisely the right way: non-consequentialists need to improve on Kant. Kant, quite famously, rejected the claim that we have duties to animals and argued instead that we have duties with regard to certain animals (or, as it is often awkwardly put, we have "indirect duties to" certain animals). Improving on Kant means, quite simply, establishing that we have duties to at least some animals. This basic idea can be expressed in other terms; differing expressions will each respectively be a better fit in different theories. So we might speak of animals having claims on us, or having rights, or being the kind of entity that can be wronged. But it's all basically the same idea (I would argue).

Why is this the agenda? Because of our case-specific intuitions. For most people, if they were to be presented with a vignette describing a pointless act of extreme violence against (say) a horse, an ape, or a dog, they would judge not only that the act was wrong but that the animal was a victim of that wrong. ${ }^{4}$ To validate this intuition it's necessary to establish that we can have duties to some animals. That this should be the agenda for non-consequentialist theories of animal ethics becomes even more clear when we consider why non-consequentialists themselves would consider animal ethics to be worth their time. If the agenda were merely to demonstrate that we can have duties with regard to animals, non-consequentialists

\footnotetext{
${ }^{4}$ Kant admits this and attempts to explain away the intuition. See his comments on amphiboly (Kant 1996: Akademie edition pagination 6:442).
} 
could be satisfied with what Kant himself said. ${ }^{5}$ So the agenda must be more ambitious, and since there's no middle ground between having duties merely with regard to animals and having duties to some animals, the agenda must be to establish that the latter is the case.

Korsgaard aims to show that Kant's theory actually allows for this. She begins by admitting that duties to animals cannot be extracted from the first formulation of the Categorical Imperative. But even from the perspective of Kantian ethics this is no major strike against the existence of duties to animals, since, according to Korsgaard (2005:98), many central duties to humans also cannot be inferred from the first formulation. So a turn to the second formulation is inevitable.

Korsgaard then asks: On what grounds are we obligated to resist treating humanity as a mere means? Here Korsgaard makes the crucial point that it is not on account of humanity possessing an out-there-in-the-world absolute value. For the Kantian, value is constructed through the will. Certain ways of acting present themselves to us in a "normatively loaded" way (Korsgaard (2005:83; see also 2009:114)), which is to say that they strike us as worth doing or worth avoiding. For instance they whet an appetite, incite a passion or arouse a curiosity (Korsgaard 2011:102), or stoke a desire or fear (Korsgaard 2013:637). Korsgaard calls these mental states incentives. She goes on to say that when an individual with the capacity for reflective endorsement endorses an incentive she confers value on the incentivized way of acting and makes it an end in itself (Korsgaard (2011:106; see also 2005:92-3, 2012:8 and 2013:640)). So if we are obligated to resist treating humanity as a mere means, this must be because we reflectively endorse humanity - the capacity for

\footnotetext{
${ }^{5}$ This is true even for those non-consequentialists who aren't Kantians, since there's nothing distinctly Kantian about Kant's argument for duties with regard to animals. What he says could be taken on board by just about anyone.
} 
reflective endorsement itself. And in reflectively endorsing humanity, we impose on ourselves a law requiring that we respect humanity (Korsgaard (2005:93-5; 2012:910)).

What's key to Korsgaard's argument regarding animals is her further claim that our humanity is not the only aspect of our nature that we reflectively endorse. She contends that we reflectively endorse a range of incentives that fall under our animal nature, such as seeking pleasure, sex, and play and avoiding pain, mutilation and loss of control (Korsgaard (2005:105; 2011: 108; 2013:643)).

This gets us to the endorsement of animal nature, but it still doesn't get us to duties to animals. This is because we haven't yet established the scope of our selflegislative ability. Isn't it possible for a human to reflectively endorse only her own animal nature, and thus to lay down for herself only a very narrow law requiring that she not treat her own animality as a mere means (Korsgaard 2005:100f)? Of course by the same token one might wonder whether one could avoid incurring duties to other humans all the while endorsing one's own humanity, which would of course be to prove too much.

Korsgaard responds that when one reflectively endorses an incentive one does not merely endorse one's own instantiation of it. Rather, one endorses it in general (Korsgaard $(2005: 104 ; 2012: 13)) .{ }^{6}$ So the laws one gives to oneself through reflective endorsement include within their scope all the beings that possess the incentive being endorsed (Korsgaard (2005:105; 2012:13)). Thus others' ends bind each of us.

\footnotetext{
${ }^{6}$ In an interesting footnote, Korsgaard (2005:104) offers the following analogy: ...imagine a white male who claims that in valuing his own freedom he is only valuing the freedom of white males: if, unknown to himself, he turned out to be a black woman...then he would agree that his freedom doesn't matter. Our response would be that either he's insincere or deceiving himself, that he's suffering from a failure of reflective imagination.
} 
I have two worries about Korsgaard's argument here. First, assuming that it shows us that animals' ends ground, by way of the formula of humanity, limits on how we are morally permitted to behave, it doesn't actually show that abiding by those limits is a duty to animals. Korsgaard says it does, but she has a very weak notion of 'duty to'. She contends that there are two ways in which an entity can be the kind of entity (an end-in-itself) to whom one can have duties. The weaker of those two ways, and the one under which animals qualify, is by being a source of legitimate claims. And what it means to be a source of legitimate claims is to be in a position to make a claim on a moral agent in the name of a law the authority of which is recognized by that agent (Korsgaard $(2005: 95-6 ; 2011: 104,109)$ ). So this is what Korsgaard is saying is true of animals when she says that we have duties to them.

The only example Korsgaard offers of how one gets to be a source of claims in this sense, aside from the argument she gives to establish that animals qualify, is from the law: she says that individuals who are protected by laws that they had no part and could have no part in creating can be sources of claims in this sense (Korsgaard 2011:107). So if Country X has a law than bans raping people regardless of their nationality, this makes each foreign visitor to country $\mathrm{X}$ a source of claims in the given sense. Each such visitor makes a claim on the citizens of Country $\mathrm{X}$ - a claim to not be raped - in the name of a law that is binding on those citizens all the while having played no part and not being the sort of person who could play a part in the creating of that law.

Note, however, that the laws of Country X might make it quite clear that violations of the prohibition on raping foreigners are to be treated as purely criminal violations, thus affording foreigners who have been raped no ability to register a civil 
complaint or demand restitution. In other words, the laws of Country X might make it quite clear that the raped party is to be afforded no standing.

Perhaps Korsgaard's point, however, is that the mere fact that the foreigner had no part and could not possibly have had a part in creating the law is insufficient to establish that she lacks standing with respect to violations of the law. ${ }^{7}$ After all, the country could afford her standing if she were raped. This is enough, it seems, to open up the possibility that animals could have standing with respect to the moral law despite having no part in creating it.

Fair enough. Now taking it as given that animals could have standing with respect to the moral law, how can we figure out whether they do? Since according to Korsgaard the moral law arises out of certain mental states (i.e., the reflective endorsement of incentives), one must look to those mental states to settle the question of whether some animal has standing with respect to the moral law it creates. And when we do this, we find no answer. There is nothing in the attitude of endorsing an incentive or refusing to endorse an incentive that could establish any fact one way or the other whether, if at some point I engage in an action that is inconsistent with my endorsement of some incentive, which of the individuals affected by that action will have standing with respect to it. The worry then is that for all Korsgaard has said there is no fact of the matter as to whether animals have standing, and thus no fact of the matter as to whether we have duties to them.

My second objection is that Korsgaard actually hasn't managed to show that animals' ends ground, by way of the formula of humanity, limits on how we are morally permitted to behave. To see why, we have to examine how prohibitions are

\footnotetext{
${ }^{7}$ Thanks to MB for helping me to see this point.
} 
extracted from the second formulation of the categorical imperative. Under the classical understanding of the second formulation, in which the concern is merely humanity, and animality is not mentioned, there are four ways of violating it:

1. Treating one's own humanity as a mere means.

2. Treating the humanity of others as a mere means.

3. Failure to treat one's humanity as an end in itself.

4. Failure to treat the humanity of another as an end in itself.

In a much earlier publication Korsgaard (1996:125-8) offers an example of each kind of violation. We need not review the examples of Type 1 and Type 3 violations, as for the purposes of this discussion we are concerned exclusively with our treatment of others (animals, specifically). This leaves Type 2 and 4. Let's begin with the latter.

Korsgaard offers, as example of a Type 4 violation, failing to promote the happiness of others. Happiness is achieved through the realization of ends that one sets for oneself, so a failure to promote the happiness of another is a failure to take seriously the value of her ends, which implies a failure to take seriously her capacity to confer value through endorsing something as an end. Consequently we have a duty to promote the happiness of others.

Now the question arises: When we amend the second formulation of the Categorical Imperative so that it mentions animality in addition to humanity, are there then more actions that constitute Type 4 violations? Could I fail to set the animality of others as an end? I might, but it's hard to see what the objection to it would be. If I fail to set the humanity of another as an end, this is objectionable because it constitutes a denial of that other to confer value on something through the act of 
reflective endorsement. Nothing analogous happens if I fail to set the animality of another as an end.

As to the Type 2 violation, Korsgaard offers the example of false promising. When people keep their promises this is an exercise of humanity-of good willing. A false promise can work only when and because others keep their promises. Therefore, false promises use the humanity of others as a mere means, and so we have a duty not to make them.

Now if we reformulate the second formulation of the Categorical Imperative so that it mentions both humanity and animality, are there then more ways of committing Type 2 violations? Can I use the animality of others as a mere means? Well I might use a woman's sex drive as a means to the satisfaction of my own. But this would be wrong only if she didn't consent. But we already knew, from having consulted the original second formulation, that it's not permissible for me to have sex with a woman without her consent. So it doesn't appear that we learn anything important by noting that the animality of another can be used as a mere means.

This is a surprising conclusion. I would guess that most people share Korsgaard's sense - and indeed even now I have to stop myself from getting carried away by the intuitive pull of it - that bringing animals and animality under the ambit of the second formulation of the Categorical Imperative must make some difference to how we're permitted to treat them. How could it be, for instance, that hunting animals for sport is not ruled out by this new formulation?

The answer, in short, is that animality was already covered by the second formulation of the Categorical Imperative before Korsgaard amended it. Some uses 
of another's animality are ruled out by the unamended formulation-namely, all those uses of another's animality that are also impermissible uses of another's humanity.

Getting someone drunk in order to make her want to have sex with you may constitute such an example. Meanwhile, the rest of the uses of another's animality are ruled in by the unamended formulation. Having sex with someone with that person's unimpaired consent would be one case.

But doesn't that mean, one might ask, that for those individuals that lack humanity the amended second formulation tells us something that we didn't know already regarding how it's permissible to treat them-namely, that we shouldn't use their animality as a mere means? The first thing to note, by way of response, is that there is a risk of going too far here. If, because I'm lazy, I train my dog to fetch my slippers, am I using an aspect of my dog's animality (namely its instinct to retrieve) as a mere means to my end? Surely we don't want to say that, since that would be to condemn such dog training as immoral. The obvious escape is to point out that there doesn't seem to be anything objectionable, from the dog's point of view, to fetching my slippers. Now there are two ways to understand this. We could simply understand this as a way of saying that such dog training doesn't make my dog unhappy, but this observation is entirely out of place when considering whether such dog training is a Type 2 violation (it seems more appropriate to the question of whether it's a Type 4 violation, but we've already seen why one cannot commit a Type 4 violation with respect to an animal). Alternatively, we could understand this as a way of saying that my dog would, if she could, consent to being trained this way. This is precisely the route the Korsgaard elects to take. She says (2011:110), "We may interact with the other animals as long as we do so in ways to which we think it is plausible to think they would consent if they could." 
The problem here is that I cannot literally imagine my dog conferring or withholding consent. My dog wouldn't be that particular dog any more if it had the capacity to consent; it would be some other being. Now I can imagine an animal just like my dog but with the added capacity for consent, and I can imagine her dissenting from certain ways of being treated. But if that's the basis for my duty to refrain from doing some particular thing to her, then it's not her that constitutes the source of that duty; rather it's the hypothetical agent I constructed. And so it's not a duty to her.

\section{Rowlands's Contractarianism}

Rowlands's goal is to develop Rawls's contractarianism and demonstrate that, contrary to what Rawls and most of his commentators have thought, Rawls's contractarianism provides the basis for ascribing rights to animals. In what follows I offer a very brief summary of Rowlands's argument, as found in chapter 6 of the revised and expanded edition of his Animal Rights: Moral Theory and Practice. It doesn't do justice to the nuance with which Rowlands approaches his subject, especially his careful exegesis of Rawls, but it will give us everything we need to assess Rowlands's case for animal rights.

The key to that case is Rowlands's view regarding the thickness of the veil of ignorance. Rowlands emphasizes that the entire construction of the original position, including the veil of ignorance, is, for Rawls, to be based on prior moral commitments. In other words, the original position is not supposed to be a morally neutral starting point. Rather, it is supposed to embody the moral convictions of 
which we are most confident and that play the most fundamental roles in our moral thought. From these convictions, via the original position thought experiment, we are supposed to be able to derive further moral constraints. Rowlands then points out that one of these central moral commitments is that if an individual is not responsible for possessing property $\mathrm{P}$, then that individual is not entitled to whatever benefits accrue from her possession of $\mathrm{P}$. This is our anti-moral arbitrariness conviction. Rowlands then makes his key move in defending animal rights: he points out being human is not something any of us are responsible for. Therefore, given that from behind the veil of ignorance we are supposed to be ignorant of whatever properties of ours we are not responsible for, the veil of ignorance must then deprive us of the knowledge of our humanity. And if we consider what set of rules we would endorse while not presupposing our humanity, we find that we would favour rules that afford many protections for animals, such as protection against being killed for food. ${ }^{8}$

As far as this goes, I say "fair enough". But how far does this get us? Rowlands (2009:119) thinks it gets us to the conclusion that animals have direct rights, for instance against being killed for food, where a direct right is a right the possession of which by $\mathrm{X}$ does not depend on the possession of a right by any other individual, Y. (Direct rights can be thought of as the correlates of Kantian duties-to.)

The problem, however, is that we certainly wouldn't want to say that anything protected by the set of rules agreed upon in the original position has direct rights. We might, for instance, adopt a rule protecting certain inanimate objects like the Egyptian pyramids, and yet we wouldn't want to say that the pyramids have direct rights.

\footnotetext{
${ }^{8}$ This strategy for incorporating animals into Rawls's contractarianism was suggested much earlier by Donald VanDeVeer (1979) and Brian Barry (1989:204).
} 
The closest Rowlands comes to responding to this objection is when he says the following:

...the scope of morality is restricted to things that an occupant of the original position could rationally worry about being. I can, in the original position, worry about being at least certain sort of non-human animal since there is something that it is like to be them (at least some of them). [...] But if I were told that I was going to be a rock then I couldn't care less what happened to me (and rationally so). Therefore in the original position, I would not vote to include these under the scope of the principles of morality just in case I became one. The contractarian position, then, makes sentience the cut-off point for morality... (2009: 160)

There is an important ambiguity in Rowlands's use of the expression "the scope of morality" in the first sentence of the block quote and "morality" in the last. For Rowlands, these terms designate either the extent of moral protection or the extent of the possession of direct rights. If the former, then Rowlands is clearly mistaken. It is quite plausible that the set of rules that would result from our deliberations in the original position would include protection for inanimate objects like the pyramids. If the latter, then what's going on in this passage is Rowlands is changing his argument for animal rights. It would seem Rowlands realizes that the scope of direct rights will be much too broad if X's being protected by the agreed-upon rules is sufficient for X's possession of such rights, so he suddenly adopts the entirely different and incompatible position that X's being the sort of thing that there is something that it is to be like is necessary for X's possession of direct rights.

Let's set aside the worry about Rowlands's consistency and simply focus on the idea that that X's being the sort of thing that there is something that it is to be like is necessary for X's possession of direct rights. My worry is that this isn't a particularly contractarian position. One doesn't arrive at a conclusion like this by 
reasoning from a contractarian starting point — that is, by thinking about which rules could be agreed upon by self-interested contractors (perhaps from behind a veil of ignorance). Granted, from a contractarian starting point one could, indeed would, reach the conclusion that there is something very important about the distinction between beings such that there is something that it is like to be them, and other beings: namely, the existence of the former sort of beings would constrain the deliberations of a rational contractor in a way that the existence of the latter sort of beings (or objects) would not. But there is nothing particularly contractarian about saying that this difference grounds a difference in the possession of direct rights. Indeed, it is hard to see what motivation for saying this that there could be from within contractarianism.

A much more natural thing to say, from the contractarian perspective, is that whether an individual is the kind of being that can possess direct rights depends on whether he or she is, or could be, a party to the contract. The idea would be that if I violate a rule that was agreed upon, or could have been agreed upon, by you and I in a contracting situation, then I have violated a direct right of yours.

This is a much more Hobbesian way of thinking about contractarianism than Rowlands would be comfortable with. Rowlands is a Rawlsian, and he explicitly rejects the understanding of Rawlsian contractarianism on which the outcome of the original position has force in virtue of its modelling some hypothetical agreement. Rather, Rowlands (2009:136) insists, the original position simply models a certain method of moral reasoning, and what makes a moral consideration valid is that we each would arrive at it by reasoning in that way. 
I have no interest in arguing that this is a bad interpretation of Rawls or a bad version of contractarianism. I simply want to point out that once we strip contractarianism of its distinctly contract-based element, then just as in Korsgaard's theory there won't be any fact of the matter as to whether animals have rights. What we're left with is the idea that the true moral constraints are those that we would want enshrined if we reasoned about the matter in a particular way. As a solitary rational agent, thinking (from behind a veil of ignorance) about what I would want, all that would matter to me is that individuals do certain things and refrain from doing other things. Therefore, all we can get from this version of contractarianism, it seems to me, is a sorting of actions into the categories of permissible, obligatory, and impermissible. We cannot, I contend, extract from this version of contractarianism any further facts about who has rights, or claims, or is the object of duties, or can be wronged, etc. But this is the agenda for non-consequentialist theories of animal ethics.

In the end, then, Rowlands confronts the same problem that besets Korsgaard. If one has a broadly constructivist starting point, whether Kantian or Rawlsiancontractarian, one is committed to saying that certain moral constraints are the deliverances of some real or hypothetical agent's will or are the result of an agreement between the wills of multiple individuals. But what agents will is simply that certain things be done or not done. They don't will, nor can they sensibly be imagined to will, that some act constitute the wronging of somebody. So, in order to accommodate the idea that some actions constitute wronging, the constructivist needs to add to her theory the claim that when one violates one of the willed constraints one wrongs the individual or individuals whose wills set the constraints. In other words, the constructivist needs to allow for something like a pre-existing moral constraint 
against violating agreements or against subverting the will of others. This would get the constructivist to the conclusion that all individuals whose wills help to determine the constraints can be wronged. But it still wouldn't get the constructivist to the conclusion that animals can be wronged, unless animals' wills help to determine the constraints. And neither Rowlands nor Korsgaard is arguing that they do.

Admittedly, Rowlands's theory of animal ethics is an improvement on Kant's. Among theories that, like Rowlands's and Kant's, allow that some of the things we might do to animals would be wrong but cannot allow for the possibility of wronging animals there is a distinction to be made between those that allow that some of the things we might do to animals are not just wrong but non-contingently wrong. Kant's theory of animal ethics doesn't allow this, since it relies on the contingent fact that by treating animals cruelly humans can get accustomed to being cruel in general. ${ }^{9,10}$ Rowlands's theory does, since under his version of contractarianism there is not supposed to be anything contingent about what a contractor would will from behind the veil of ignorance; there is only one correct way to deliberate in the Original Position. ${ }^{11}$ Still, however, Rowlands's theory doesn't get non-consequentialists what they should want.

\section{Nussbaum's Capabilities Approach}

\footnotetext{
${ }^{9}$ This is contrary to what Timmermann (2005) argues. Timmerman's article was the first (as far as I know of) to point out the distinction within theories that don't allow for the possibility of animals being wronged between those that allow that some of the things we might do to animals are non-contingently wrong and those that do not.

${ }^{10}$ Neither can Korsgaard's, since her theory relies on the contingent fact that humans endorse certain features of their animality. (Nussbaum (2011a) notes with disapproval this feature of Korsgaard's theory.)

${ }^{11}$ Thanks to Hallie Liberto for pushing me to make this concession to Rowlands.
} 
Unlike Korsgaard and Rowlands, Nussbaum is interested in answering a question of political morality: What does the state owe to animals? ${ }^{12}$ This is a central question in her Frontiers of Justice. However, Nussbaum believes that an answer to this question should be grounded in an answer to a question of morality-full-stop: What basic entitlements do animals have? So Nussbaum's answer to the just-stated question of political morality is supposed to be established by an argument of this format:

1. Animals have basic entitlements to X.

2. The state is obligated to secure all the basic entitlements.

3. Therefore, the state is obligated to secure $\mathrm{X}$ for animals.

I want to keep our focus, for the purposes of this review, on the morality-full-stop question of how ordinary individuals should treat animals. So I'm going to focus only on premise 1 of the above argument, ${ }^{13}$ since it obviously has implications for the morality-full-stop question. ${ }^{14}$

Nussbaum contends that each individual who is capable of a dignified life is entitled to it, that living a life of dignity requires having the opportunity to flourish, and that having the opportunity to flourish involves possessing certain capabilities, ${ }^{15}$ where a capability is an ability to do something or to be something (Nussbaum

\footnotetext{
${ }^{12}$ Actually, this is a bit misleading. Korsgaard does have one publication targeted specifically at this question of political morality: Korsgaard 2013.

${ }^{13}$ I argue elsewhere that Nussbaum has no argument for premise 2. See Sachs unpublished-1.

${ }^{14}$ I may not have an obligation, as the state does (according to Nussbaum), to secure each individual's basic entitlements, but surely I have an obligation not to deprive an animal of $\mathrm{X}$ if the animal has a basic entitlement to $\mathrm{X}$.

${ }^{15}$ This argument appears in Nussbaum 2006:chap. 6, specifically pp. 326-7, 336-7 and 346-9. That chapter is Nussbaum's most extensive engagement with questions of how we should treat animals. It is an expansion of Nussbaum 2004.
} 
2006:70). So for Nussbaum the " $X$ " in the above argument is to be replaced by a list of capabilities.

Knowing even this much about Nussbaum's theory makes it clear that she is not going to confront the problem that beset Korsgaard and Rowlands. There is no worry about a failure to ground duties to animals, since Nussbaum's theory is built out of the idea an entitlement to dignity. So if we deprive animals of $X-$ the designated capabilities — we will be guilty of wronging them.

Nussbaum's theory, then, emphasizes the moral importance of the individual. So although her theory gives a central place to the idea of flourishing, it is not a brand of utilitarianism. Whereas the utilitarian begins by identifying a good or a set of goods of central moral importance, and then instructs us to act so as to bring about as many of those goods as possible, Nussbaum believes that we have a separate obligation, for each individual, to not deprive that individual of the goods that are particular to that individual — the goods that constitute its flourishing. ${ }^{16}$ (Nussbaum (2011b:158) departs from utilitarianism again in insisting that sentience is not sufficient for an animal's being the kind of thing that can have entitlements; she says sentience plus "agency or striving" is necessary. ${ }^{17}$ )

Therefore a central challenge for Nussbaum is to say how we are to determine for each individual what would constitute flourishing for that individual. It is here, I contend, that her approach is at its weakest. Whereas one might have thought that what constitutes flourishing for an individual depends exclusively on the properties of that individual, Nussbaum holds that what constitutes flourishing for an individual depends on its species membership. Nussbaum (2006:365) says that for each species

\footnotetext{
${ }^{16}$ Nussbaum (2006:338-46) herself emphasizes how her theory departs from utilitarianism.

${ }^{17}$ Nussbaum (2006: 361-2) used to agree with the utilitarians on this point.
} 
there is a species norm - an "account of central capabilities" - that "tells us what the appropriate benchmark is for judging whether a given creature has decent opportunities for flourishing."

Part of Nussbaum's argument ${ }^{18}$ for the superiority of the species-relative account is straightforwardly practical and strategic. Nussbaum worries that if we release ourselves from the obligation to think of disabled humans as humans and as having the same mode of flourishing as other humans, then we make it all too easy to deceive ourselves about what it's possible for us to do to support their flourishing, and we thereby render it quite likely that political institutions will end up doing very little for them.

Still, however, we can reasonably understand Nussbaum as holding that it's true that an individual's flourishing is a matter of her achieving a species-relative set of capabilities. In any event, if Nussbaum's capability theory is to provide the philosophical basis for answers to moral (as opposed to political) questions about our treatment of animals, we have to interpret it as including this claim. This is what I will do moving forward.

Nussbaum's capability theory is flawed, I contend, on account of its inability to give a good answer to this question: For any given species, how can we come up with an account of the basic capabilities that are essential for the flourishing of a member of that species? In the human case Nussbaum says we should start with an ethically evaluative idea of human nature; an idea of features of human life "that seem so normatively fundamental that a life without any possibility of exercising one of them, at any level, is not a fully human life..." (Nussbaum 2006:181). In earlier

\footnotetext{
${ }^{18}$ Specifically, the part that appears in Nussbaum 2006:188-90.
} 
works Nussbaum (1992) spelled this out in greater detail. Basically she proposed that we generate a list of such features via inductive generalization from cases. We are to take real or imagined cases of individuals who are biologically human but lack some capability that biological humans usually have and then ask ourselves whether that person is living a fully human life. If we have the intuition that they are, then this supports the generalization that the capability in question isn't central for flourishing as a human. And vice-versa.

Is it reasonable to assume that Nussbaum is still committed to this methodology? In Frontiers of Justice she doesn't even mention it; instead she emphasizes, in line with her broadly political agenda in that book, that the list of capabilities will have to be the result of public reasoning and political negotiation (Nussbaum 2006:160-64, 298-305). Still, however, I think she's committed to it. In order for a public reasoning and political negotiation to get us anywhere, there have to be inputs to the process; people have to bring opinions to the table. The question is, how are people going to generate judgments regarding which capabilities are central for human flourishing? It seems that they would have to use Nussbaum's inductive generalization method, as it's not clear what the alternative would be.

As to how we should come up with accounts of flourishing for the other species, Nussbaum has never said anything. In Frontiers of Justice Nussbaum (2006:392-401) offers conclusions regarding what the central aspects of flourishing for animals are, but they come off more as predictions regarding what would be agreed to after a process of public reasoning and political negotiation than as substantive assertions regarding flourishing. This, again, leaves a question as to how 
the judgments that constitute the inputs to such a process could be generated, and again I think the only option is to use the inductive generalization method.

Now that we see how important the inductive generalization method is for Nussbaum's project, we should try to open it up and see how it works. Given that Nussbaum is encouraging us to ask ourselves questions of the form, "Is capability X an essential element of flourishing for a member of Species Y”, she must believe that species distinctions are normatively relevant. My question is this: In virtue of what are species distinctions normatively relevant?

Nussbaum (2006:363) explicitly rejects views on which humans are set apart from other animals by bearing a special relation to God or God's will. Nor does she endorse a strictly biological notion of species, as she's willing to say that some individuals that are born of human parents are not human (Nussbaum 2006:187). ${ }^{19}$ And this is as it should be. The theistic theory of the normative relevance of humanity is highly contentious; meanwhile the agenda for biologists is to carve out species distinctions in the way that best facilitates scientific inquiry, and it would therefore be an enormous coincidence of if their distinctions mapped on to anything of normative significance. ${ }^{20}$

I propose that the key is to be found in Nussbaum's (2011b:161) claim that "the species plays a role in giving us a sense of a characteristic form of life that ought to be promoted." Nussbaum doesn't say what a form of life is, but fortunately we can appeal to Philippa Foot (and by extension Michael Thompson, since Foot draws on Thompson), the contemporary philosopher who has done the most to substantiate

\footnotetext{
${ }^{19}$ Nussbaum's rejection of the strict biological conception of species is also suggested by her comment on James Rachels (Nussbaum 2006:363).

${ }^{20}$ This is old news. I rehash it more thoroughly and provide relevant citations in Sachs unpublished-2 (chap. 4).
} 
such talk. According to Foot, different kinds of being display differing forms of life. For each kind, we can identify true "Aristotelian categoricals" such as "rabbits eat grass", or "wolves hunt in packs". A set of such categoricals defines the kind's form of life by expressing how that "kind of plant or animal, considered at a particular time and in its natural habitat, develops, sustains itself, defends itself, and reproduces" (Foot 2001:29). And the life form, in turn, "determines how an individual plant or animal should be" (Foot 2011:33). This gets us to the idea that there is normative relevance to form of life. Now it's an easy step to the normative relevance of species: we simply need to add that there is a distinction in form of life everywhere there is a species distinction, which is probably just what Nussbaum meant to say in that passage quoted at the outset of this paragraph.

The problem for Nussbaum here is that she's importing too much Aristotelianism into her ethical theory. Of course, as if this needed to be said, there is plenty of value, and perhaps a great deal worth retaining, in Aristotle's ethics and politics, and Nussbaum is quite forthright in drawing upon his ideas. But this particular bit of Aristotelianism - this talk of forms of life, is dubious. Nussbaum herself has nearly ceased such talk entirely. Whereas it was rampant in her earlier work, ${ }^{21}$ she deploys it sparingly her two most recent books on the capabilities approach. ${ }^{22}$ It's as if Nussbaum senses that she's wading into dangerous territory with such talk.

What's so worrying about talk of forms of life? For Aristotle, the idea of a form of life is a component of his natural teleology. (Nussbaum (2006:182), incidentally, says that the capabilities theory doesn't rely on natural teleology; I'm

\footnotetext{
${ }^{21}$ See, for instance, Nussbaum 1992.

${ }^{22}$ I've identified just one use of such language in Nussbaum $2011 \mathrm{~b}$, namely in the passage I quoted above. I've also found just one use of such language in Nussbaum 2006 (on p. 78).
} 
suggesting here that it does.) Natural teleology is the view that the nature of a thing determines how that thing ought to be. And for Aristotle, a thing's nature depends on its form of life, which in turn depends on what kind it's a member of. I find this all pretty objectionable, but for the sake of argument I'll allow it to go unchallenged. What I want to resist is the final element of Aristotle's natural teleology: the idea that the salient kind for a living thing is its species.

Nussbaum has to hang on to that last component, otherwise the whole project of coming up with a distinct capability list for each species is undermined (or, alternatively, Nussbaum has to abandon the "form of life" argument for the normative relevance of species distinctions). This would be a profound problem for Nussbaum, as a large part of her agenda is to establish that cognitively impaired humans have entitlements that are different from those of similarly cognitively sophisticated animals. Nussbaum has no argument for this claim if she is forced to renounce her contention that distinctions in modes of flourishing line up with species distinctions. For then it would make no difference that cognitively impaired humans and animals are members of different species.

But the problem is that if we admit, as Nussbaum did, that how biologists draw species distinctions makes it highly doubtful that such distinctions could map on to anything normatively relevant, then, since the species distinctions with which we operate just are the ones from biology, we have no reason to believe that there is a distinction in form of life everywhere there is a distinction in species. There could instead be more fine-grained distinctions in form of life, perhaps corresponding to ordinary distinctions in sub-species, or more coarse-grained distinctions in form of 
life, corresponding to ordinary distinctions at the level of phylum or genus. Foot (2001:29) herself admits as much.

This is not to say that when one asks oneself the question, "Is capability $\mathrm{X}$ an essential element of flourishing for a member of Species Y," one will be unable to come up with an answer. So this is not to say that Nussbaum's inductive generalization method will fail on account of our being unable to form the judgments that constitute the inputs to the method. Rather, it is to say that the method will fail if, and to the extent that, people accept that the way biologists draw species distinctions makes it highly dubious that such distinctions carry normative weight.

So Nussbaum's method of inductive generalization for generating capability lists for each of the species can be completed only to the extent that people fail to acknowledge what Nussbaum herself admits about the normative relevance species distinctions. Therefore, the viability of Nussbaum's inductive generalization strategy for discovering what would constitute flourishing for different beings requires the persistence of judgments that she rejects.

\section{Conclusions}

I began this essay by endorsing a specific agenda for non-consequentialist theories of animal ethics: they have to improve on Kant, where improving on Kant means showing how certain things we do to animals aren't merely wrong but constitute 
wronging of the animal itself. I then argued that three contemporary nonconsequentialists - Korsgaard, Rowlands and Nussbaum — have each failed to do this.

It is difficult to draw any general conclusions from each of these three failures. Although from a certain reflective distance the problems that beset Korsgaard and Rowlands can be seen as broadly of the same kind, as I explained at the end of $\S 2$, there are no defects in common to all three theories. Allowing ourselves to speak very abstractly, perhaps the most that can be said is that non-consequentialists would do well to experiment with approaching animal ethics more individualistically. This means seeing the animal as a source of moral constraints in virtue of its intrinsic features, such that its similarity to humans and its species membership make no difference to the existence or content of the constraints.

\section{References}

Barry, B. 1989. Theories of Justice. Hemel Hempstead: Harvester-Wheatsheaf. Foot, P. 2001. Natural Goodness. New York: Oxford University Press.

Kant, I. 1996. The Metaphysics of Morals, ed. Mary Gregor. Cambridge: Cambridge University Press.

Korsgaard, C. 1996. Kant's formula of humanity. In Korsgaard, C., Creating the Kingdom of Ends, 106-32. Cambridge: Cambridge University Press.

Korsgaard, C. 2005. Fellow creatures: Kantian ethics and our duties to animals. In The Tanner Lectures on Human Values: Volume 25: 2005, ed. G. B. Peterson, 77-110. Salt Lake City: The University of Utah Press.

Korsgaard, C. 2009. Self-Constitution: Agency, Identity, and Integrity. New York: Oxford University Press. 
Korsgaard, C. 2011. Interacting with animals: A Kantian account. In The Oxford Handbook of Animal Ethics, eds. T. Beauchamp and R.G. Frey, 91-118. New York: Oxford University Press.

Korsgaard, C. 2012. A Kantian case for animal rights. In Animal Law: Tier und Recht, eds. J. Hänni, M. Michel and D. Kühne, 3-27. Zurich: Dike Verlag.

Korsgaard, C. 2013. Kantian ethics, animals, and the law. Oxford Journal of Legal Studies 33: 629-48.

Kumar, R. 2008. Permissible killing and the irrelevance of being human. The Journal of Ethics 12: 57-80.

McMahan, J. 2002. The Ethics of Killing. New York: Oxford University Press.

McMahan, J. 2005. Animals. In A Companion to Applied Ethics, eds. R.G. Frey and C.H. Wellman, 525-36. Malden, Mass.: Blackwell Publishing.

McMahan, J. 2008. Challenges to human equality. Journal of Ethics 12: 81-104.

Nussbaum, M.C. 1992. Human functioning and social justice: In defense of Aristotelian essentialism. Political Theory 20: 202-46.

Nussbaum, M.C. 2004. Beyond 'compassion and humanity': Justice for nonhuman animals. In Animal Rights: Current Debates and New Directions, eds. C.R. Sunstein and M.C. Nussbaum, 229-320. New York: Oxford University Press. Nussbaum, M.C. 2006. Frontiers of Justice. Cambridge, Mass.: The Belknap Press. Nussbaum, M.C. 2011a. The capabilities approach and animal entitlements. In The Oxford Handbook of Animal Ethics, eds. T.L. Beauchamp and R.G. Frey, 22851. New York: Oxford University Press.

Nussbaum, M.C. 2011b. Creating Capabilities. Cambridge, Mass.: The Belknap Press. 
Rowlands, M. 2009. Animal Rights: Moral Theory and Practice. Basingstoke, Hampshire: Palgrave Macmillan.

Sachs, B. Unpublished-1. Teleological contractarianism.

Sachs, B. Unpublished-2. Explaining right and wrong.

Timmermann, Jens. 2005. When the tail wags the dog: Animal welfare and indirect duty in Kantian ethics," Kantian Review 10: 128-49

VanDeVeer, D. 1979. Of beasts, persons, and the original position. The Monist 62: 368-77. 